\title{
The impact of ship emission controls recorded by cloud properties
}

Edward Gryspeerdt ${ }^{1}$, Tristan Smith $^{2}$, Eoin O’Keeffe ${ }^{2,3}$, Matthew Christensen ${ }^{4}$, and Fraser Goldsworth ${ }^{1,4}$

${ }^{1}$ Space and Atmospheric Physics Group, Imperial College London, UK

${ }^{2}$ UCL Energy Institute, University College London, UK

${ }^{3}$ University Maritime Advisory Services, London, UK

${ }^{4}$ Department of Physics, University of Oxford, UK

Correspondence: Edward Gryspeerdt (e.gryspeerdt@imperial.ac.uk)

\begin{abstract}
Shipping comprises around $18 \%$ of the global emission of sulphur containing species $\left(\mathrm{SO}_{x}\right)$, some of which oxidise to form sulphate aerosols. This aerosol is an efficient cloud condensation nuclei (CCN), such that ship emissions into low clouds modify cloud properties, creating features known as "shiptracks". Aerosols also pose a major health risk, leading to effects to reduce ship fuel sulphur content (FSC) globally and in specific "emission control areas" (ECAs).

Here we show how previous regulation in FSC content has produced a significant change in cloud properties. We also show that the occurrence of shiptracks is strongly controlled local meteorology, with a clear contribution from ship $\mathrm{SO}_{x}$ emissions, such that regulation has led to an almost complete elimination of shiptracks in existing ECAs. By connecting the properties of shiptracks to the ships that generate them, we demonstrate how shiptracks and clouds can provide information on ship $\mathrm{SO}_{x}$ emissions under suitable meteorological conditions.
\end{abstract}

\section{Main text}

Almost all cloud droplets form on a particle of atmospheric aerosol, acting as a cloud condensation nucleus (CCN). By burning sulphur-containing fuel, ships emit sulphur oxides $\left(\mathrm{SO}_{x}\right)$ which oxidise to form particles of sulphate, enhancing the local $\mathrm{CCN}$ population ${ }^{1}$. This increase in $\mathrm{CCN}$ increases the cloud droplet number concentration $\left(N_{d}\right)$, an effect that can increase cloud reflectivity ${ }^{2}$. An increase in $N_{d}$ may further modify clouds and precipitation processes, generating additional changes in the radiative properties of the cloud field ${ }^{3}$.

The modification of cloud properties has a significant effect on the climate ${ }^{4}$, but the magnitude of this effect is uncertain due to the difficulty in isolating the aerosol impact on a cloud from that of the local meteorology $5 ; 6$. As point sources of aerosol, ships create linear perturbations in cloud properties, features known as a "shiptracks" ${ }^{7}$. As ships are assumed to emit aerosol independent of the large-scale atmospheric conditions, shiptracks are used as "natural experiments", isolating the impact of aerosol on cloud properties $8 ; 9 ; 10 ; 11 ; 12$.

Shiptracks are usually found in regions of large amounts of low cloud, such as the western coasts of continents ${ }^{13}$. Tracks identified using satellite data typically have lengths of over $100 \mathrm{~km}$, lasting for almost 20 hours $^{14}$, although the modification of shiptracks to cloud properties can persist for a number of days, influencing large areas ${ }^{15}$ and are not always clearly visible ${ }^{16}$. Although ships can provide local heat fluxes of up to $30 \mathrm{MW}$ and moisture fluxes of $2 \mathrm{~kg} \mathrm{~s}^{-117}$, a comparison of different ship 
types during the Monterey Area Shiptrack campaign ${ }^{18}$ demonstrated that the aerosol emissions of the ship were the primary control on the formation of shiptracks ${ }^{1}$, with heavy fuel oil (HFO) powered ships producing stronger cloud perturbations than liquified petroleum gas or nuclear powered vessels ${ }^{17}$.

This strong link of shiptrack occurrence to aerosol suggests that they are a suitable way of monitoring ship fuel sulphur content (FSC). FSC is regulated according to standards set by the international maritime organisation (IMO), with a global limit of 3.5\% S (by mass). Two emission control areas are also defined, one around the coast of North America and a second covering the North Sea, Baltic Sea and English Channel ${ }^{19}$. In these regions, FSC was unrestricted before 2005 and limited to $1 \%$ in 2010 and $0.1 \%$ in $2015^{19}$. In 2020, new worldwide restrictions will be introduced, limiting FSC to $0.5 \%$ globally. Recent advances in ship monitoring using satellites allows the position and speed of ships to be monitored globally ${ }^{20}$, which can be combined with the physical properties of the ship and the FSC to estimate sulphur emissions ${ }^{21}$.

Building on previous studies conducted as part of the MAST campaign, we use this new satellite dataset to connect ship emissions to shiptrack properties at a larger scale. Previous studies have been limited to around 1,500 shiptracks globally $22 ; 11$ and 200 co-locations between ships and the associated shiptrack ${ }^{23}$. They have usually only focussed on a specific season $24 ; 8$ or location (tracks that intersect CALIOP/CLOUDSAT ${ }^{9}$ ) and as a result the actual frequency of their occurrence could not be calculated. In this work, we use multiple years of satellite and re-analysis data to develop a high-density dataset of over 10,000 tracks located around ECAs, including over 1,200 co-locations between ships and shiptracks, key for computing the occurrence frequency of shiptracks and how it relates to meteorological conditions. Accounting for the strong impact of local meteorology in determining the formation of shiptracks, we show that FSC regulations have already had a significant impact on shiptrack formation. We also demonstrate that the estimated ship emissions can be used to predict the properties of shiptracks, opening a pathway to the retrieval of ship emissions from space.

\section{Identifying shiptracks}

Shiptracks are identified in imagery from the moderate resolution imaging spectroradiometer (MODIS) onboard the Aqua satellite. Preliminary identification is conducted using the day-microphysics composite ${ }^{25}$, created from the MYD021KM calibrated radiance product. An RGB composite image and the adiabatic droplet number concentration ${ }^{26}$, created from the MYD06L2 product ${ }^{27}$ are used to provide further information during the identification, helping to exclude other linear features such as contrails. Two regions are investigated, a region surrounding the European ECA (42-64N, 12W-8E) and one covering the ECA region off the coast of California (30-45N, 115-130W). Visual inspection of all possible MODIS images was essential in order to characterise ship track frequency of occurrence and its connection to meteorology and emission. All the daytime MODIS Aqua granules intersecting these regions for the years of 2003 and 2015 are examined, along with 2014 for the Californian region. Many granules only partially intersect this region, shiptracks that occur outside the study region are recorded as long as they are in one of these granules. Further details on the identification procedure are given in the methods section.

In total, 10,033 MODIS images are examined and 13,699 tracks are identified. 9,161 of these are in the Californian region and 4,538 in the European region. In the Californian region during 2015, ship positions are determined using the Automated 

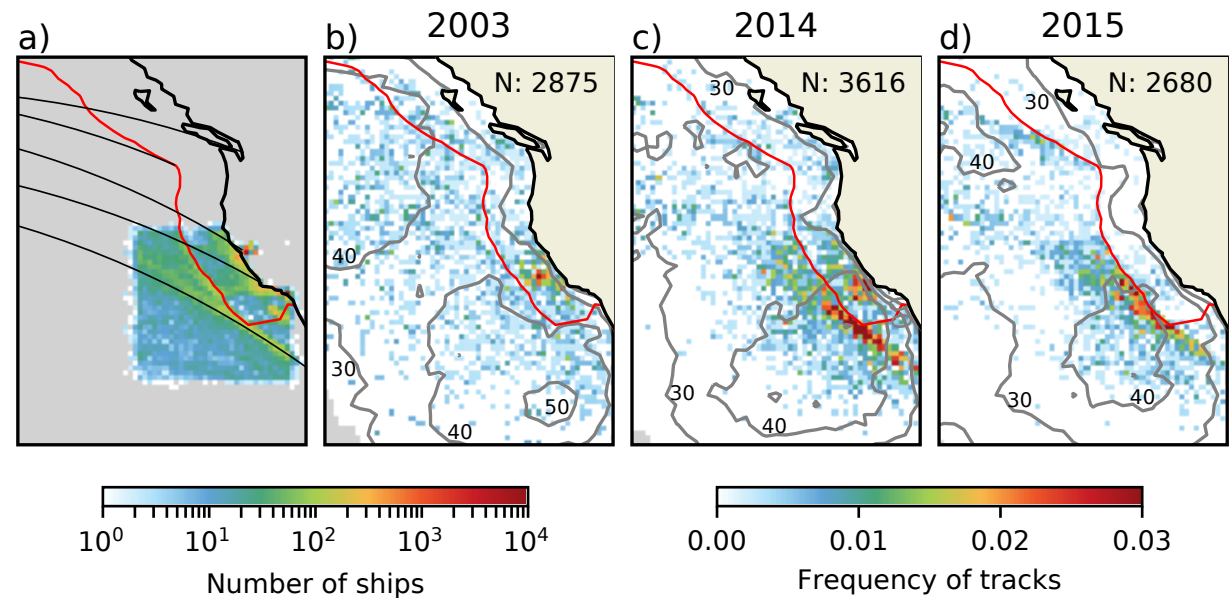

Figure 1. Inter-annual variation in shiptrack locations a) Locations of ships determined using AIS data at the satellite overpass time in 2015. Thin black lines show major shipping routes. b-d) Frequency of occurrence of identified shiptracks for the years 2003, 2014, 2015. The red line is the US Pacific sulphur ECA. Thin grey lines show the percentage annual average liquid cloud fraction from MODIS. The number of identified tracks each year is in the upper right of each subplot. Locations viewed by fewer than 100 granules are greyed out.

Identification System (AIS), a maritime collision avoidance system. AIS transmitters are installed on all ships larger than 300 tons, broadcasting identity, position, speed and other safety information ${ }^{28}$. These ship positions are used to estimate shiptrack locations for the year 2015 together with simple 2D lagrangian trajectories estimated using reanalysis wind data. These estimated locations are only used to assist in the manual identification of shiptracks, rather than as the sole method of

5 identification. This avoids biases in the driving reanalysis data affecting shiptrack statistics. 1,299 shiptracks are matched to AIS tracks for the year 2015.

\section{Shiptrack occurrence}

The occurrence of shiptracks is controlled by two main factors, the occurrence of suitable low cloud and the presence of a ship emitting aerosol. Fig. 1 highlights the impact of both of these factors. In 2003, 2867 tracks are identified in the greater Californian region. These are concentrated close to the coast, particularly in the region between the ports of San Francisco/Oakland/Richmond and Los Angeles/Long Beach. Increased concentrations of shiptracks are visible in major shipping lanes leaving Vancouver/Seattle, San Francisco and Los Angeles. As shown in previous work, the occurrence of shiptracks is closely related to the liquid cloud fraction (at $1^{\circ}$ by $1^{\circ}$ scales), with higher shiptrack occurrence found in regions with a large amount of low cloud.

Between 2010 and 2015 (Fig. 1c), FSC inside the ECA was limited to 1.0\%. This does not produce a significant change in the occurrence of shiptracks, with no clear change being observed across the boundary of the ECA. A large concentration of tracks 
is observed along the south-western corner of the ECA. This may indicate ships avoiding the ECA, but it is approximately aligned with the great-circle route between Panama (via False Cape) and Tokyo and so may indicate an increase in activity along a pre-existing route. Part of the increase in shiptrack number in this region is due to the anomalously high low cloud coverage in the region in 2014 producing conditions more conducive to shiptrack formation.

The introduction of the $0.1 \%$ FSC limit in the ECA produces a dramatic change between 2014 and 2015, with an almost complete absence of shiptracks in the ECA region. This is in stark contrast to 2003, which has a very similar low cloud pattern. Some shiptracks are observed near Vancouver, which may be due to the fleet-average enforcement regime used by the Canadian government. A strong increase in tracks along the edge of the Canadian section of the ECA suggests that ships may be optimising their route to spend as little time within the ECA as possible.

Similar reductions in the occurrence of shiptracks are observed in the North Sea/English Channel ECA (Fig A1). However, due to the smaller size of the ECA and more polluted nature of the region leading to lower frequency of shiptracks in this area, the difference in shiptrack occurrence across the edge of the ECA is not as clear as the Californian case.

\section{Meteorological controls}

There is a clear impact of meteorological properties on shiptrack formation (Fig. 2). Factors controlling low cloud occurrence are particularly strongly related to shiptrack occurrence. Fig. 2 shows the distribution of meteorological properties from track forming ships compared to all the ships in the database. In the Californian region, ship position is not a function of meteorology, shown by the overlap of the distributions for all the ships (blue) and the distributions for all ships with the AIS positions but a randomised day of the year to account for any possible correlation between ship routing and meteorology (green).

As in ${ }^{23}$, boundary layer height (Fig. 2a) is found to be a controlling factor, confirming the decrease in shiptracks in very thin boundary layers. However, low troposphere stability ${ }^{30}$ is the dominant control on shiptrack formation probability (Fig. 2b), with shiptrack formation probability being significantly reduced in unstable atmospheres. The increase in track formation at lower $\mathrm{RH}_{850 h P a}$ is partially due to the correlation with LTS, but it persists even in cases where there is a large amount of low cloud (Fig. A2). As drier above cloud layers allow stronger cloud top cooling and hence in-cloud updraughts, this indicates an increase in track formation in cases with stronger updraughts, which are more likely to be aerosol-limited ${ }^{31}$. This requirement for low cloud is clear in the $1^{\circ}$ by $1^{\circ}$ MODIS properties, with track formation being more common in cases with a large liquid cloud fraction (Fig. 2e) and higher cloud top pressures (Fig. 2f). The reduction in cases with high cloud tops is due to an increase in multi-layer situations obscuring the stratocumulus deck. However, there is also a significant peak in shiptracks occurring at low liquid cloud fraction, which may be related to shiptracks forming in collapsed marine boundary layers ${ }^{32}$.

The background aerosol environment also has an effect on the formation of shiptracks. There is a slight reduction in the 30 occurrence of shiptracks at higher background $N_{d}$ (Fig. 2g) and a large reduction at high MERRA2 SO 4 (Fig. 2h), demonstrating that polluted environments prevent shiptrack formation ${ }^{33}$.

Although there is significant variation in the meteorological properties in the region, there is not a trend in the properties (Fig. 2) that could explain the reduction of shiptracks in the ECA (Fig. 1). The only variable that shows a significant difference 


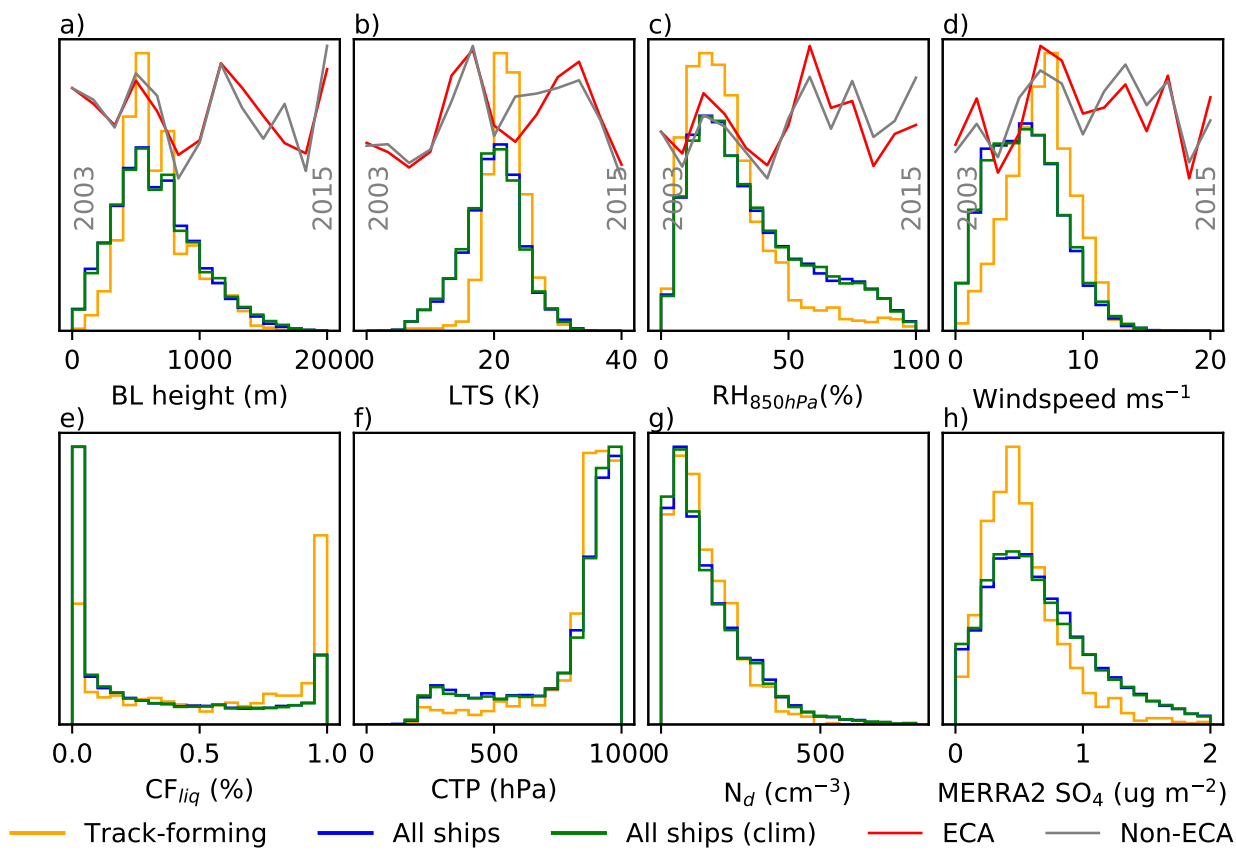

Figure 2. The relationship between meteorology and track formation probability Histograms of meteorological properties for all ships (blue), ships forming shiptracks (orange) and climatological ship cases (green). a) Boundary layer height, b) low troposphere stability, c) Relative humidity at $850 \mathrm{hPa}$ and d) $10 \mathrm{~m}$ windspeed, determined using ERA-Interim, with a linear interpolation between the nearest sixhour analysis timesteps. e) Liquid cloud fraction, f) cloud top pressure, g) adiabatic cloud droplet number concentration are from the MODIS Aqua $1^{\circ}$ by $1^{\circ}$ daily mean product (MYD08_D3), with a temperature correction following ${ }^{29}$. h) Background $\mathrm{SO}_{4}$ concentration from the MERRA2 reanalysis. The red and grey lines indicate the annual anomaly with respect to the mean of each parameter from 2003 to 2015 within and outside the ECA region respectively.

in the anomaly inside compared to outside the ECA is $\mathrm{RH}_{850 h P a}$, where a decrease within the ECA during 2015 would lead to an increase in the number of tracks, rather than the observed decrease (Fig. 2c).

Ship emissions are also an important controlling factor in the occurrence of shiptracks (Fig. 3). $\mathrm{SO}_{x}$ emissions for each ship are estimated following the IMO Third GHG study ${ }^{21}$. Fuel usage is estimated based on the physical properties and observed speed of the ship. Assumptions of the hull fouling and deterioration, along with the weather state represent key uncertainties in the fuel usage, at around 20\% combined. Assuming average FSC outside the ECAs and a maximum possible value inside, this fuel usage is converted to $\mathrm{SO}_{x}$ emissions. The assumed FSC is based on IMO measurements and does not account for any non-compliance with FSC regulations. Further details are given in the methods section.

The majority of ships in the region have a very low expected $\mathrm{SO}_{x}$ emission, due to the dominant effect of the ECA. However, the emissions distribution of ships forming tracks is skewed to higher emissions. About half of this difference is due to geographical factors. Ships outside the ECA (With higher emissions) are also in a meteorological environment more conducive 


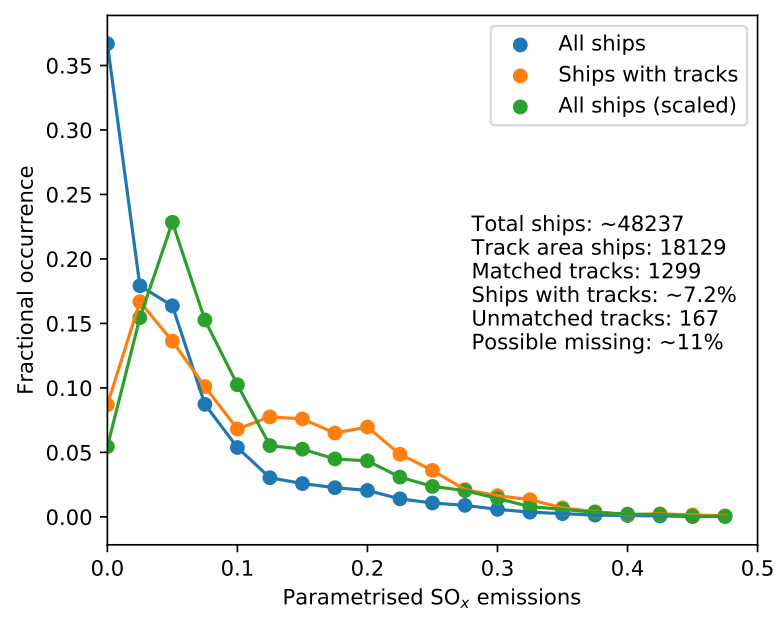

Figure 3. Frequency of track occurrence by parametrised emissions The blue line shows the normalised distribution of emissions from all the ships in the database and the orange line the emissions from track-forming ships. The green line is the emissions distribution from all ships scaled to the same geographical distribution as the track-forming ships.

to the formation of tracks. When the ship emissions distribution is sampled to account for this geographic distribution (Fig. 3, green line), the distribution is skewed to higher emissions, but does not replicate the distribution of ships forming tracks. The higher average emissions from track-forming ships further supports FSC regulation as the cause of the dramatic reduction in shiptracks in the ECA region in 2015.

\section{$5 \quad 5$ Shiptrack properties}

The detectability of shiptracks necessarily depends on the methods used to locate them. Regions with low variability in the cloud field improve detectability, whilst high variable regions, such as open-celled regions reduce detectability ${ }^{16}$. In addition, manually identified tracks may suffer from selection biases. Investigating the relationship between shiptrack properties and ship emissions reduces the impact of this bias, because as long as the identification threshold is met, there are no other constraints on the shiptrack properties.

The properties of the shiptracks are characterised using a modified version of the algorithm in ${ }^{8}$ and $^{9}$, able to cope with several shiptrack in close proximity and poor accuracy in the hand-logging of the shiptracks. The data is further subset to select cases where there is a good match between the ship and the associated track (as specified in the methods), reducing the sample size to 420 .

Using this restricted subset of tracks, the enhancement factor $\left(N_{p o l} / N_{c l n}\right)$ estimated using $N_{c l n}$ and the ship $\mathrm{SO}_{x}$ emissions (see supplementary information) is compared to the measured enhancement factor (Fig $4 \mathrm{a}$ ). The enhancement factor is strongly controlled by $N_{c l n}$, with larger enhancements at lower $N_{c l n}$, but the inclusion of information on the ship emissions allows the 

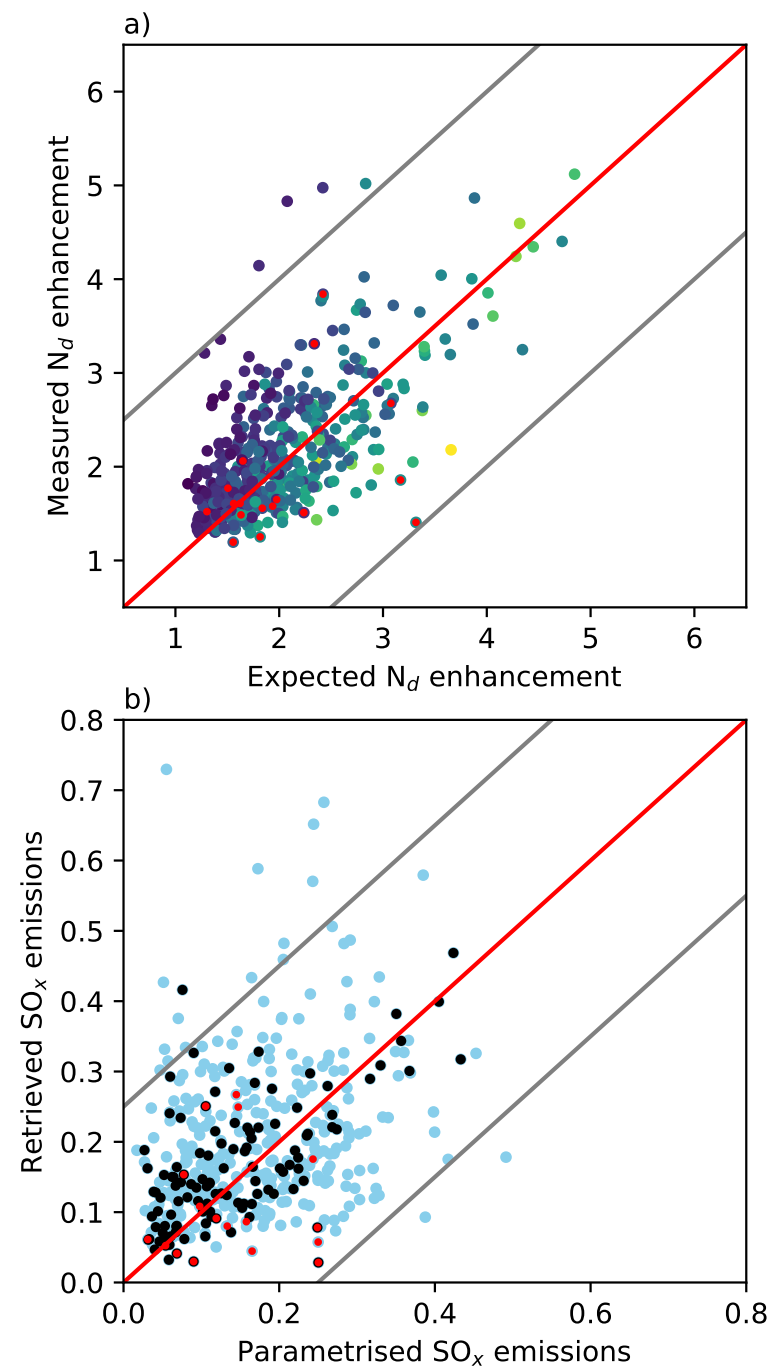

Figure 4. Using ship emissions to estimate shiptrack properties a) The measured $N_{d}$ enhancement $\left(N_{\text {pol }} / N_{c l n}\right)$ as a function of the expected $N_{d}$ enhancement given $N_{c l n}$ and the parametrised ship emissions. Colours are the parametrised ship emissions. b) $\mathrm{SO}_{x}$ emissions retrieved using the shiptrack properties as a function of the parametrised $\mathrm{SO}_{x}$ emissions. Black points have $N_{c l n}<50 \mathrm{~cm}^{-3}$. Red points in both plots are located in the ECA region. 
prediction of the enhancement factor with a correlation of 0.69. This further demonstrates the important role of ship emissions in controlling the properties of shiptracks, driving the changes observed in Fig. 1.

Similarly, if the enhancement factor is known, the ship emissions can be retrieved (Fig. 4b). The agreement is weaker than for the enhancement factor, with a correlation of only 0.38. However, the correlation between the parametrised and retrieved $5 \mathrm{SO}_{x}$ emissions rises to 0.61 when only cases with $N_{c l n}<50 \mathrm{~cm}^{-3}$ are considered (Fig. $4 \mathrm{~b}$, black points), due to the larger enhancement factor and hence greater signal to noise at lower values of $N_{c l n}$. This demonstrates the possibility of satellite retrievals of ship emissions under appropriate meteorological conditions.

\section{Discussion and conclusions}

The difficulty of isolating the aerosol influence on cloud properties has limited how accurately aerosol-cloud interactions can be constrained by observations. By emitting aerosol independently of the local meteorology, shiptracks provide a natural experiment, allowing the aerosol impact to be isolated. Previous studies have investigated the properties of shiptracks in a qualitative sense ${ }^{8 ; 9 ; 10 ; 11 ; 12}$, in this work, we link ship emissions to shiptrack properties, providing the first quantitative measure of the impact of known sources of sulphate aerosol emitted from ships on shiptrack properties at a large scale. We demonstrate that while meteorology, particularly low troposphere stability, is a key control on the occurrence of shiptracks, the enhancement of $N_{d}$ within shiptracks can be accurately predicted using retrieved cloud properties and estimates of the ship $\mathrm{SO}_{x}$ emissions. While meteorological factors are shown to be the primary controls on shiptrack occurrence, the spatial patterns of shiptrack occurrence cannot be explained by variation in these cloud properties. As the spatial and temporal patterns align with changes in ship fuel sulphur content, this provides some of the clearest evidence of the impact of ship aerosol on cloud properties, recording the changes in regulations of ship fuel sulphur content.

Uncertainties remain, particularly in the ship emission parametrisation. Currently, specific adjustments are not made for the unknown impact of sea state on fuel consumption. Given the impact of windspeed on shiptrack formation (Fig. 2), this may be generating uncertainty in the instantaneous emissions.

The identification of shiptracks is subjective, being conducted by hand. Automated methods for shiptrack identification are in development and will be able to examine potential sampling biases in future work. The ECA boundary is not used in the identification step, to reduce the possibility of such a sampling biases. However, the change in shiptrack probability across the ECA boundary is easily observed in individual images (Fig. A3).

The impact of ship emissions on the droplet enhancement within shiptracks provides further evidence of the aerosol impact, independent of a possible sampling bias. The correlation between the predicted and measured droplet enhancement along with the correlation between the estimated and retrieved $\mathrm{SO}_{x}$ emissions demonstrates the potential for future quantitative studies into shiptrack properties. In addition, it lays the groundwork for a method to retrieve ship emissions using satellites, a area likely to grow in importance with the upcoming introduction of stringent global restrictions on ship fuel sulphur content. 
Author contributions. EG designed the study. TS, EO prepared the ship emission data. MC, FG designed and implemented the shiptrack extraction algorithm. EG performed the analysis. All of the authors discussed the results and commented on the manuscript.

Competing interests. The authors have no competing interests.

Acknowledgements. The authors would like to thank Michael Richardson for assistance in constructing the shiptrack identification application and Peter Lelliott (UCL Energy Institute) for his assistance in preparing the ship emission data. The MODIS and MERRA-2 data was downloaded from the NASA Goddard Earth Sciences (GES) Data and Information Services Center (DISC). The ERA5 data is from the Copernicus Climate Change Service (C3S) Climate Data Store (CDS). The AIS data was obtained from ExactEarth. EG was supported by an Imperial College Junior Research Fellowship. FG was supported by funding from the Ogden Trust.

\section{References}

10 [1] Durkee, P. A. et al. The impact of ship-produced aerosols on the microstructure and albedo of warm marine stratocumulus clouds: A test of MAST hypotheses 1i and 1ii. J. Atmos. Sci. 57, 2554-2569 (2000).

[2] Twomey, S. Pollution and the planetary albedo. Atmos. Environ. 8, 1251-1256 (1974).

[3] Albrecht, B. A. Aerosols, cloud microphysics, and fractional cloudiness. Science 245, 1227-1230 (1989).

[4] Boucher, O. et al. Clouds and Aerosols (Cambridge University Press, 2014).

15 [5] Quaas, J., Stevens, B., Stier, P. \& Lohmann, U. Interpreting the cloud cover - aerosol optical depth relationship found in satellite data using a general circulation model. Atmos. Chem. Phys. 10, 6129-6135 (2010).

[6] Grandey, B. S., Stier, P. \& Wagner, T. M. Investigating relationships between aerosol optical depth and cloud fraction using satellite, aerosol reanalysis and general circulation model data. Atmos. Chem. Phys. 13, 3177-3184 (2013).

[7] Conover, J. H. Anomalous cloud lines. J. Atmos. Sci. 23, 778-785 (1966).

[8] Segrin, M. S., Coakley, J. A. \& Tahnk, W. R. MODIS observations of ship tracks in summertime stratus off the west coast of the united states. J. Atmos. Sci. 64, 4330 (2007).

[9] Christensen, M. W. \& Stephens, G. L. Microphysical and macrophysical responses of marine stratocumulus polluted by underlying ships: Evidence of cloud deepening. J. Geophys. Res. 116, D03201 (2011).

[10] Christensen, M. W., Suzuki, K., Zambri, B. \& Stephens, G. L. Ship track observations of a reduced shortwave aerosol indirect effect in mixed-phase clouds. Geophys. Res. Lett. 41, 6970-6977 (2014). 
[11] Toll, V., Christensen, M., Gassó, S. \& Bellouin, N. Volcano and ship tracks indicate excessive aerosol-induced cloud water increases in a climate model. Geophys. Res. Lett. 44, 12,492-12,500 (2017).

[12] Gryspeerdt, E. et al. Constraining the aerosol influence on cloud liquid water path. Atmos. Chem. Phys. 19, 5331-5347 (2019).

5 [13] Schreier, M., Mannstein, H., Eyring, V. \& Bovensmann, H. Global ship track distribution and radiative forcing from 1 year of AATSR data. Geophys. Res. Lett. 34, 17814 (2007).

[14] Schreier, M., Joxe, L., Eyring, V., Bovensmann, H. \& Burrows, J. P. Ship track characteristics derived from geostationary satellite observations on the west coast of southern africa. Atmos. Res. 95, 32-39 (2010).

[15] Goren, T. \& Rosenfeld, D. Satellite observations of ship emission induced transitions from broken to closed cell marine stratocumulus over large areas. J. Geophys. Res. 117, 17206 (2012).

[16] Possner, A., Wang, H., Wood, R., Caldeira, K. \& Ackerman, T. P. The efficacy of aerosol-cloud radiative perturbations from near-surface emissions in deep open-cell stratocumuli. Atmos. Chem. Phys. 18, 17475-17488 (2018).

[17] Hobbs, P. V. et al. Emissions from ships with respect to their effects on clouds. J. Atmos. Sci. 57, 2570-2590 (2000).

[18] Durkee, P. A., Noone, K. J. \& Bluth, R. T. The monterey area ship track experiment. J. Atmos. Sci. 57, 2523-2541 (2000).

15 [19] IMO. International convention for the prevention of pollution from ships: Annex VI (2005).

[20] Eriksen, T., Høye, G., Narheim, B. \& Meland, B. J. Maritime traffic monitoring using a space-based AIS receiver. Acta Astronautica 58, 537-549 (2006).

[21] Smith, T. W. P. et al. The Third IMO GHG Study (International Maritime Organization (IMO), 2015).

[22] Campmany, E., Grainger, R. G., Dean, S. M. \& Sayer, A. M. Automatic detection of ship tracks in ATSR-2 satellite imagery. Atmos. Chem. Phys. 9, 1899-1905 (2009).

[23] Durkee, P. A. et al. Composite ship track characteristics. J. Atmos. Sci. 57, 2542-2553 (2000).

[24] Coakley, J. A. et al. The appearance and disappearance of ship tracks on large spatial scales. J. Atmos. Sci. 57, 2765-2778 (2000).

[25] Rosenfeld, D. et al. High-resolution (375 m) cloud microstructure as seen from the NPP/VIIRS satellite imager. Atmos. Chem. Phys. 14, 2479-2496 (2014).

[26] Quaas, J., Boucher, O. \& Lohmann, U. Constraining the total aerosol indirect effect in the LMDZ and ECHAM4 GCMs using MODIS satellite data. Atmos. Chem. Phys. 6, 947-955 (2006). 
[27] Platnick, S. et al. The MODIS cloud optical and microphysical products: Collection 6 updates and examples from terra and aqua. IEEE T. Geosci. Remote 55, 502-525 (2017).

[28] IMO. Safety of life at sea convention (2002).

[29] Gryspeerdt, E., Quaas, J. \& Bellouin, N. Constraining the aerosol influence on cloud fraction. J. Geophys. Res. 121, 3566-3583 (2016).

[30] Klein, S. A. \& Hartmann, D. L. The seasonal cycle of low stratiform clouds. J. Climate 6, 1587 (1993).

[31] Twomey, S. The nuclei of natural cloud formation part II: The supersaturation in natural clouds and the variation of cloud droplet concentration. Geofisica Pura e Applicata 43, 243-249 (1959).

[32] Ackerman, A. S., Toon, O. B. \& Hobbs, P. V. Dissipation of marine stratiform clouds and collapse of the marine boundary layer due to the depletion of cloud condensation nuclei by clouds. Science 262, 226-229 (1993).

[33] Noone, K. J. et al. A case study of ship track formation in a polluted marine boundary layer. J. Atmos. Sci. 57, 2748 (2000).

[34] Randles, C. A. et al. The MERRA-2 aerosol reanalysis, 1980 onward. part i: System description and data assimilation evaluation. J. Climate 30, 6823-6850 (2017).

15 [35] McCoy, D. T. et al. The global aerosol-cloud first indirect effect estimated using MODIS, MERRA, and aerocom. J. Geophys. Res. 122, 1779-1796 (2017).

[36] Grosvenor, D. P. et al. Remote sensing of droplet number concentration in warm clouds: A review of the current state of knowledge and perspectives. Rev. Geophys. (2018).

[37] Abdul-Razzak, H., Ghan, S. J. \& Rivera-Carpio, C. A parameterization of aerosol activation: 1. single aerosol type. J. Geophys. Res. 103, 6123-6131 (1998).

[38] Rosenfeld, D. Suppression of rain and snow by urban and industrial air pollution. Science 287, 1793-1796 (2000). 


\section{Appendix A: Methods}

\section{A1 Shiptrack identification}

Shiptracks are identified manually, using data from the MODIS Aqua MYD021KM calibrated radiances product and the cloud product $^{27}$. Shiptracks are initially located using the day microphysics image ${ }^{25}$, a composite of visible, near and thermal infra-

5 red channels. This allows shiptracks to be distinguished from other linear features such as contrails. A visible RGB image and the retrieved cloud droplet number concentration $\left(N_{d}\right)$ is used for further information in unclear cases.

Shiptrack locations are estimated for each ship in the database at the time of each image using ECMWF ERA5 winds to derive a 2D lagrangian trajectories, with a 30 minute advection timestep for 10 hours previous to the satellite overpass. This allows the identification of the generating ship even in cases where there is no clear head and a significant distance separation between the ship and the shiptrack (the 90th percentile distance is around $100 \mathrm{~km}$ ).

The meteorological properties for the shiptrack are characterised at the first location where the shiptrack becomes visible, as this is more representative of the conditions for shiptrack formation than those at the ship, especially if the shiptrack and ship are separated by a significant distance. The properties are from the ECMWF ERA-Interim reanalysis, regridded to a $1^{\circ}$ by $1^{\circ}$ resolution. The MODIS properties used to characterise shiptrack formation are from the Level $31^{\circ}$ by $1^{\circ}$ product. The $N_{d}$ is calculated following the method of ${ }^{26}$, using the temperature correction from ${ }^{29}$. The reanalysis background $\mathrm{SO}_{4}$ is from the MERRA2 reanalysis ${ }^{34}$ at $900 \mathrm{hPa}^{35}$, with the nearest neighbour value from the native resolution product (approximately $0.5^{\circ}$ by $0.5^{\circ}$ ) considered characteristic of the shiptrack.

\section{A2 Shiptrack properties}

The pixels defining the shiptrack are identified using a modified version of the method in ${ }^{8}$ and ${ }^{9}$. Each track is split into $20 \mathrm{~km}$ segments. For each segment, a linear regression of $\mathrm{N}_{d}$ with cross track distance is used to determine the background and points more than 1.67 standard deviations above this background are considered polluted. A new background is calculated without these polluted pixels and a new set of polluted pixels is identified. This process continues until the polluted pixels are unchanged between iterations. Regions of polluted pixels intersecting the identified track are considered part of the track, other polluted pixels are removed from the analysis. A background $\mathrm{N}_{d}$ is then calculated from pixels between 4 and $14 \mathrm{~km}$ from the edge of the polluted region, excluding any previously identified polluted pixels. Following ${ }^{36}$, pixels with a solar zenith angle greater than $65^{\circ}$, a $5 \mathrm{~km}$ cloud fraction less than $90 \%$ and a sub-pixel reflectance variability (Cloud_Mask_SPI) greater than 30 are also removed due to the increased retrieval uncertainty in these situations.

For comparison with the ship emissions estimates, shiptrack properties are restricted to the region within 4 hours of emission (as calculated using the lagrangian trajectory model). Tracks used for Fig. 4 must also contain more than 75 polluted pixels and have a normalised distance between the observed and estimated track locations of less than 0.75 , ensuring the identification of the correct ship for each shiptrack. The control region is taken as the range $4-14 \mathrm{~km}$ outside the track on either side. 


\section{A3 Ship emissions parametrisation}

Ship emissions are estimated at the level of individual ships following the bottom-up methodology outlined in the Third IMO Greenhouse Gas Study ${ }^{21}$. A brief description is given here with more detail and validation in the report. This method combines the ship activity data from AIS with technical data about the ship type, propulsion and auxiliary power requirements based on

5 the IHS Fairplay database. The resistance to ship motion is assumed to be primarily hydrodynamic, such that it is primarily a function of ship speed and draught. The power requirement is modified by constant factors to account for hull fouling and weather. Combining the power requirement with a fuel consumption based on engine type and load and a fuel sulphur content ( $0.1 \%$ inside the ECA, $2.5 \%$ outside), the $\mathrm{SO}_{x}$ emissions are then estimated.

The quantified emission uncertainty for the dominant ship types in this study (container and bulk carriers) is approximately $1014 \%$. This uncertainty comes primarily from uncertainties in the ship speed and draught, such that it reduces for ships with more regular and complete AIS reports. Additional uncertainty comes from the fuel sulphur content which is assumed as the global fleet heavy fuel oil average $(\approx 2.5 \%)$. More complete data in the future would be expected to provide a more accurate picture of the ship $\mathrm{SO}_{x}$ emissions.

Around $11 \%$ of identified tracks in the Californian region cannot be clearly linked to an individual ship using the AIS 15 records. This does not mean that $11 \%$ of ships are missing from the database, only that they cannot be accurately localised in the satellite overpass window. 